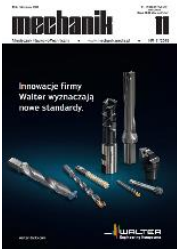

How to cite this article:

Authors: Marek Kołodziej, Paweł Karolczak

Title of article: „Analysis of the impact of milling strategies on the surface roughness of 6060 aluminum alloy”

Mechanik, No. 11 (2019)

DOI: https://doi.org/10.17814/mechanik.2019.11.98

\title{
Analysis of the impact of milling strategies on the surface roughness of 6060 aluminum alloy
}

\section{MAREK KOŁODZIEJ \\ PAWEL KAROLCZAK *}

Dr inż. Marek Kołodziej, marek.kolodziej@pwr.edu.pl, https://orcid.org/0000-0001-6916-8520 - Politechnika Wrocławska, Wrocław, Polska

Dr inż. Paweł Karolczak, pawel.karolczak@pwr.edu.pl, https://orcid.org/0000-0002-0595-1580 - Politechnika Wrocławska, Wrocław, Polska

The article presents the results of research on the impact of the selected 6060 aluminum alloy milling strategy on surface roughness. Its assessment was based on the main roughness parameters in 2D and 3D. In addition, studies on the impact of tool extension in the holder on the obtained surface roughness were cited.

KEYWORDS: milling, roughness

\section{Introduction}

Over the past few decades, important progress has been made in the field of machining, which was a result of the development of CNC machine tools, cutting tools (including tool materials and coatings), control systems and information systems.

IT systems for supporting work of engineers are more frequently used. They facilitate works related to structure design, developing manufacturing technologies or organisation of the production process. In the case of machining CAM programs permit the easy generation of complex tool path. Such programs support e.g. milling of complex components with one fastening - using more than three controlled axes. In connections with a many possibilities to create tool paths in CAM software, the question arises, how to choose the most favourable path due to technological effects (such as surface roughness) and tool durability [1-5].

\section{Test methodology}

The study focused on aluminum alloy, which is characterized by high mechanical resistance, good corrosion resistance, high impact resistance, middle fatigue resistance and good weldability. This material applies in production: doors, windows, balustrades, cars bodies and trailer supporting elements, buses and trucks.

The research work was carried out on vertical machining center VF-1 from Haas. During test was used double-blade folding mill APX3000R182SA16ELA (version with ling handle) from Mitsubishi Materials, providing high performance in 3D milling operations and possibility of diagonally inserting. The mill is equipped with AOGT123604PEFR-GM inserts - also from Mitsubishi Materials - which guarantee more effective machining over a wide range of parameters.

During the experiment were adopted three different groove milling strategies (taking into account tool path), carried out with three different values of the tool sliding out of the holder. It was checked how the tool sliding out affects worked surface roughness.

Dimension of sample from aluminum alloy 6060 and dimension of grooves are shown in fig. 1.

The first strategy consists of classic grooves machining - tool path is shown in fig. 2. The following parameters have been used: rotational speed $n=5305 \mathrm{rpm}$, cutting speed $v_{\mathrm{c}}=300 \mathrm{~m} / \mathrm{min}$, feed per blade $f_{\mathrm{z}}=0,1$ $\mathrm{mm} /$ blade.

In the second strategy, tool path was based on trochoidal curve (fig. 3), and cutting parameters were as follows: rotational speed $n=5305 \mathrm{rpm}$, cutting speed $v_{\mathrm{c}}=300 \mathrm{~m} / \mathrm{min}$, feed per blade $f_{\mathrm{z}}=0,15 \mathrm{~mm} / \mathrm{blade}$, constant cutting width $a_{\mathrm{e}}=7,2 \mathrm{~mm}$, wrap angle $\varphi=156,9^{\circ}$. 
In the third strategy, the tool make motions across helix (fig. 4), and cutting parameters were as follows: rotational speed $n=5305 \mathrm{rpm}$, cutting speed $v_{\mathrm{c}}=300 \mathrm{~m} / \mathrm{min}$, feed per blade $f_{\mathrm{z}}=0,1 \mathrm{~mm} / \mathrm{blade}$, feed speed across helix $=530 \mathrm{~mm} / \mathrm{min}$, helix angle $=2^{\circ}$.

The roughness measurements were carried out on milling groove front and side surfaces with different values of the tool sliding out of the holder: $26 \mathrm{~mm}, 36 \mathrm{~mm}$ and $46 \mathrm{~mm}$. The mill sliding out was measured as distance between its end and spindle front.

Measuring stand is shown in fig. 5. Measuring distance length was $4 \mathrm{~mm}$, for profile filtering was used Guassian filter. For the assessment of surface roughness was selected $R a$ parameter. Whilst its offers poor information about the marked profile, and its interpretation is difficult (from a practical point of view), this parameter is widely used for roughness surface description in industrial conditions, because it shows low variability regardless of roughness measurement methods.

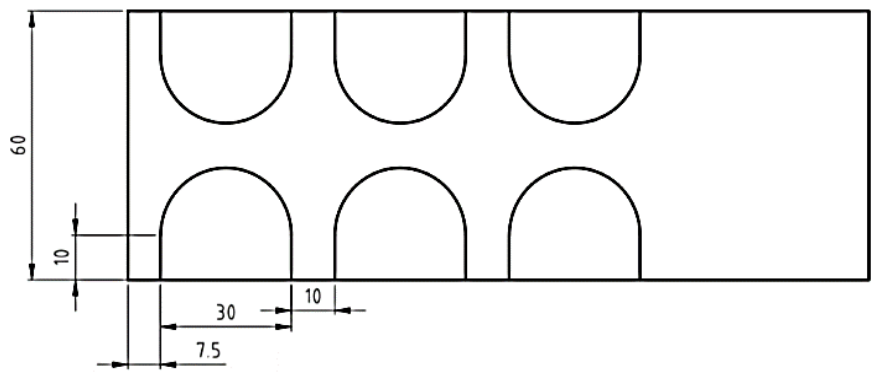

Fig. 1. Dimensions of the tested sample

a)

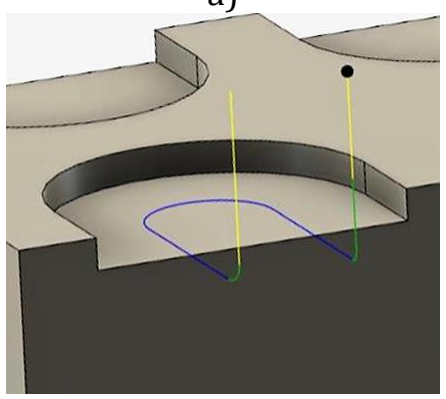

b)

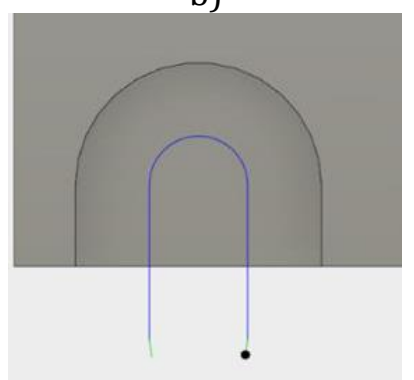

Fig. 2. Tool path in the first machining strategy: a) isometric view, b) top view

a)

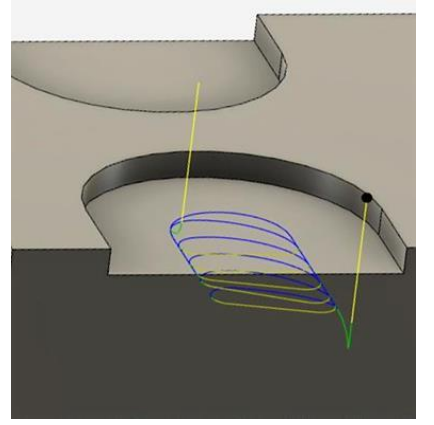

b)

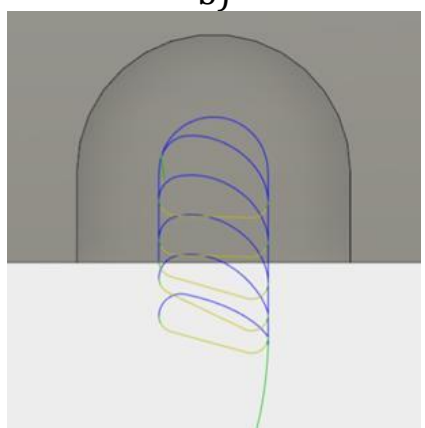

Fig. 3. Tool path in the second machining strategy: a) isometric view, b) top view

a)

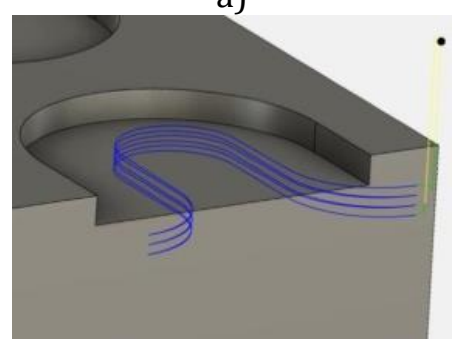

b)

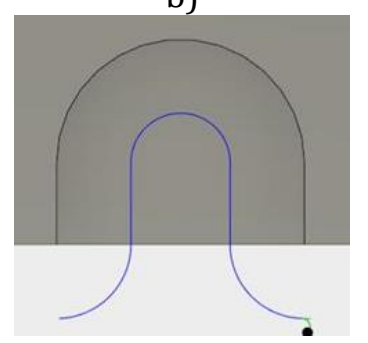

Fig. 4. Tool path in the third machining strategy: a) isometric view, b) top view 


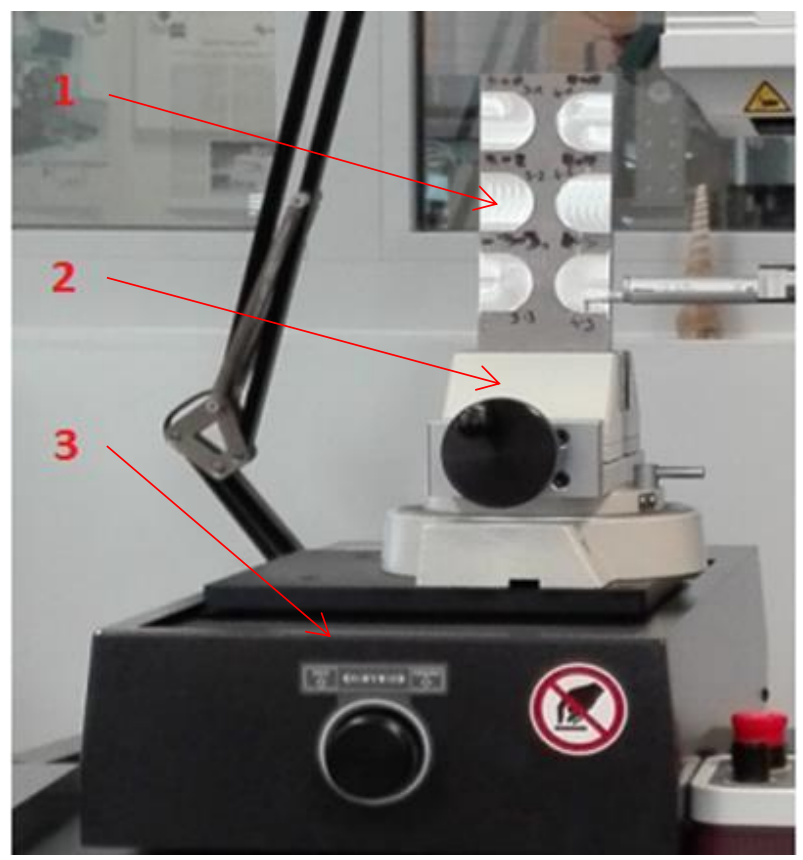

Fig. 5. Measuring stand: 1 - sample tested, 2 - rotary vice, 3 - $Y$-axis sliding table

\section{Tests results}

The analysis of the quality of obtained surfaces (fig. 6) has started with visual inspection. Traces on the machined surface are correlated with the path generated in a given machining strategy. In the case of the first strategy there are slightly visible, in the case of second strategy - very clear (it's easy to see stroke of trochoidal curve), and in the case of third strategy - the slightest.

Parameter $R a$ values for particular milling strategies with different tool sliding out of the holder are shown in figs. 7 and 8.

If we compare results from measurements of groove face surface for first milling strategy and particular tool sliding out of the holder it can be noticed that parameter $R a$ has the highest values in relation to the other strategies. The tool sliding out of the holder cause that the value $R a$ change is also the biggest, which might indicate unstable working conditions of mill, which is heavily loaded and wears faster.

On the groove side surface have been observed even greater differences of surface roughness for different milling strategies. For second and third strategies tool sliding out from holder not have a major impact on the groove side surface. However, strategy based on grooves classical machining is characterized by the greatest value and variability of $R a$ parameter.

The studies also compared machining time for particular strategies. The results are presented in fig. 9 .

There is no doubt that the shortest machining time, reaching only $4 \mathrm{~s}$, has been achieved with first strategy. Trochoidal machining is characterized by longer working time due to longer distance, which tool has to go (fig. 10). The machining according to the third strategy was the longest. Compared to the first strategy machining time was almost six times longer. Auxiliary movements, which took almost $1 / 3$ of total time dedicated to machining have a major impact on it.

a)

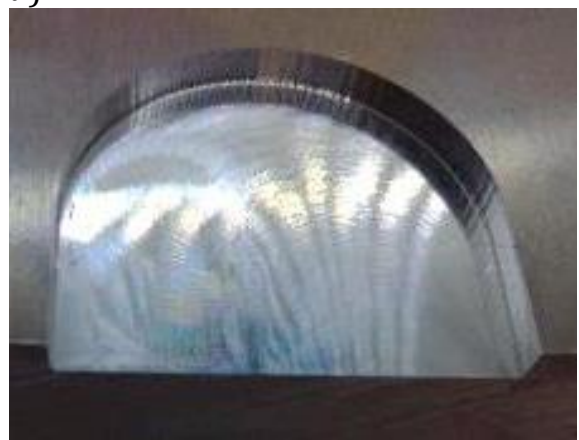

b)

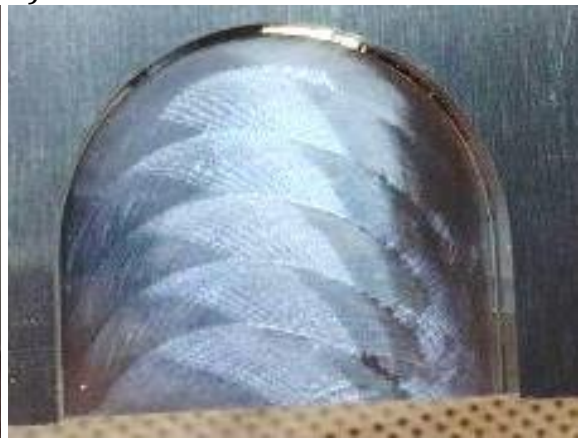

c)

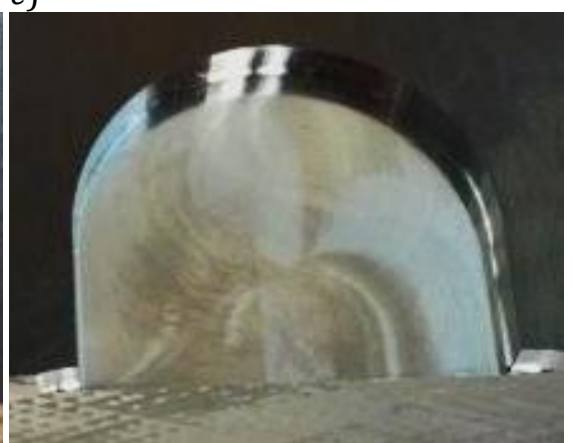

Fig. 6. Traces on the surface after treatment: $a$ ) first strategy, b) second strategy, $c$ ) third strategy 


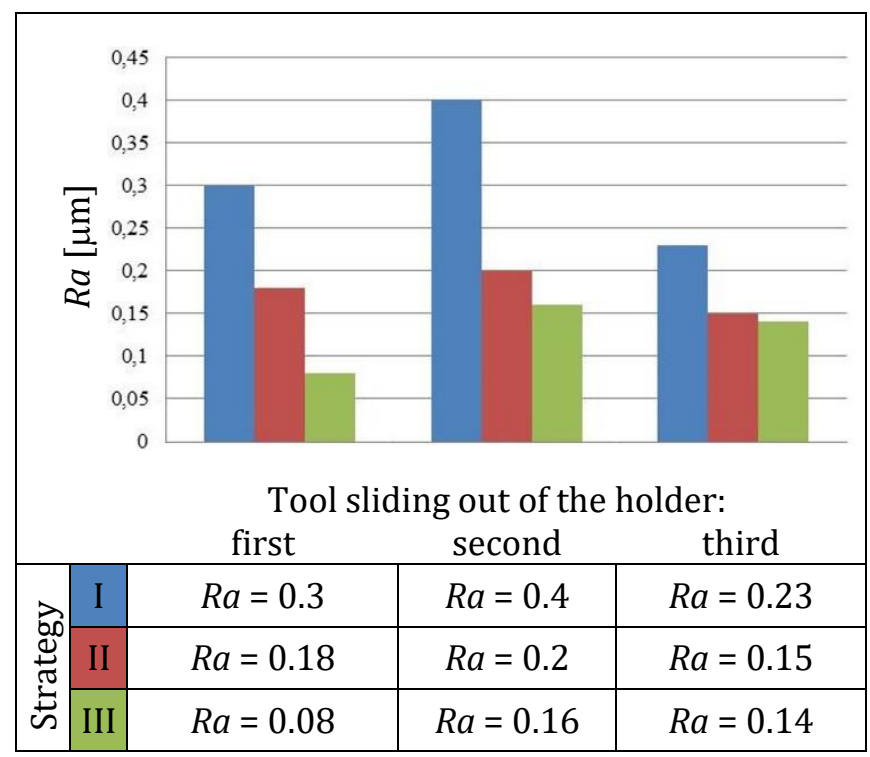

Fig. 7. Diagram of the groove face roughness depending on the milling strategy and the tool sliding out of the holder

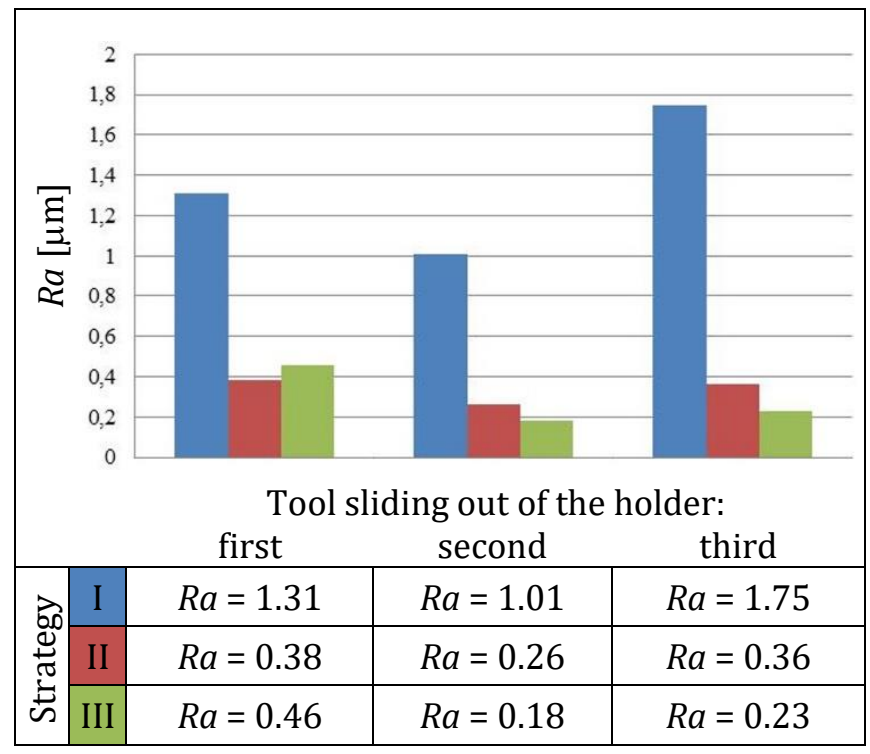

Fig. 8. Roughness chart of the lateral surface of the groove depending on the milling strategy and the tool sliding out of the holder

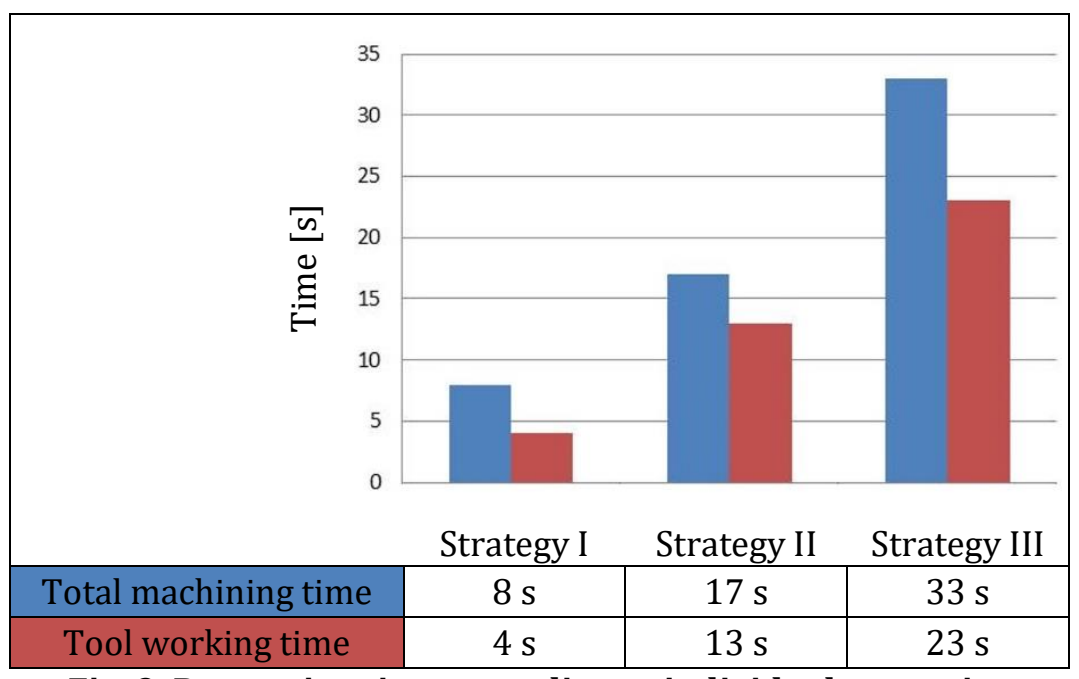

Fig. 9. Processing time according to individual strategies 


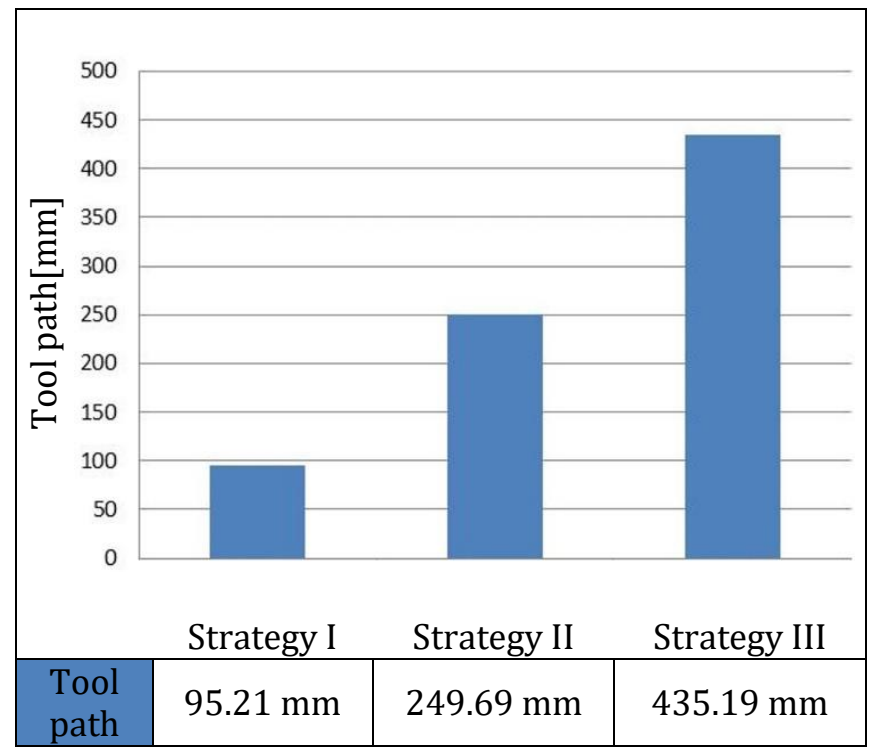

Fig. 10. Tool path in individual machining strategies

\section{Summary}

The choice of strategy is no easy task and depends on many factors, among other: machining time, cutting forces, expected surface state after machining and the path, with tool has to go. The tool path selection also has an impact on manufacturing process state - one of its elements is the machining strategy.

Studies compares three different machining strategies taking into account finished surface roughness, machining time and distance, which cutting tool had to go. Because of groove face roughness parameter, the first choice would be third strategy. Not always the face surface quality is the main priority. In the case of lateral surface of the groove, a similar roughness was received after machining with second and third strategy. As you have seen, classic machining operate in compliance with first strategy is less favourable than measured parameters of face roughness and groove side surface. This is clear particularly from groove side surface - here differences parameter value $R a$, are two or even three times (for larger tool removal). Due to travelled tool distance and machining time could be chosen the first strategy.

Because of studied machined surface parameters is favourable the second strategy. Tool path is typical of trochoidal machining. One of the main parameters, which are controlled during machining is cutting width. In these studies it was $40 \%$ of tool width and it was too big, because cutting tools manufacturers recommend that this parameter value oscillated within the range from $7 \%$ to $10 \%$ of tool diameter. In trochoidal machining, should not reduce its time through increasing cutting width. It would be better to increase feed.

Strategies based on insertion motion, type "ramp" are interesting machining methods, which allow obtaining surfaces with low roughness. That was the nature of third strategy. In this case feed value, inclination angle of helix - from $2^{\circ}$ to $8,6^{\circ}$ (tool manufacturer gives this value as maximum) also can be increased. This treatment would reduce machining time and tool path, which in third strategy was much longer then in the first strategy, for which was adopted maximum machining parameters.

\section{REFERENCES}

[1] Habrat W. „Obsługa i programowanie obrabiarek CNC. Podręcznik operatora”. Krosno: Wydawnictwo KaBe, 2007.

[2] Oczoś K., Kawalec A. „Kształtowanie metali lekkich”. Warszawa: Wydawnictwo Naukowe PWN, 2012.

[3] Pieśko P. „Badania wpływu sztywności statycznej frezów trzpieniowych na dokładność geometryczna przedmiotów wykonywanych ze stopów aluminium". Lublin: Politechnika Lubelska, 2014.

[4] Sandvik Polska. „Poradnik obróbki skrawaniem”. Warszawa, 2012.

[5] Zalewski A. „Skracanie czasu obróbki na frezarkach CNC na podstawie okresowej analizy warunków skrawania". Inżynieria Maszyn. 17, 2 (2012). 